\section{ONOMAREDIN}

Revista semestral de lingüística, filología y traducción
PONTIFICIA UNIVERSIDAD CATÓLICA DE CHILE FACULTAD DE LETRAS

\title{
Verbos deponentes en la Aulularia de Plauto
}

Deponent verbs in Plautus's Aulularia

\author{
David Antonio Roa Nova \\ Universidad Metropolitana de Ciencias de la Educación \\ Chile
}

\section{(c) $\underset{\mathrm{BY}}{\ominus} \bigodot_{\mathrm{ND}}$}

David Roa Nova: Centro de Estudios Clásicos Giuseppina Grammatico Amari, Facultad de Historia, Geografía y Letras, Universidad Metropolitana de Ciencias de la Educación, Chile.

| Correo electrónico: droanova@hotmail.com 


\section{Resumen}

En este trabajo se analizan las formas verbales, en especial los verbos deponentes, que aparecen en una obra plautina: Ia Aulularia. El análisis verbal comprende las nociones de transitividad e intransitividad léxica, tiempo y modo, con el objetivo de apreciar a grandes rasgos algunas características de su empleo sintáctico, la forma de implicación del sujeto, el contexto en que son utilizados y su clasificación según el tipo de proceso o clase verbal a la que pertenecen. Un $65 \%$ registró una construcción intransitiva. Se registró un aumento de usos de las formas deponentes (sin especificación de modo) en pasajes donde los interlocutores hacen referencia a su apreciación subjetiva del entorno. Los verbos de mayor frecuencia fueron los que denotan un proceso verbal, con un $36,4 \%$, y los de procesos mentales, con un $28 \%$.

Palabras clave: verbos deponentes; Aulularia; proceso verbal; transitividad; intransitividad.

\section{Abstract}

In this paper we analyze the verbal forms, especially deponent verbs, which appear in a work by Plautus: the Aulularia. Verbal analysis includes the notions of lexical transitivity and intransitivity, tense and mood, in order to appreciate broadly the use of some syntactic features, the form of involvement of the subject, the context in which they are used, and their classification according to the process or verbal class to which they belong. $65 \%$ reported an intransitive construction. There was an increase of deponent forms' applications (without specifying mood) in passages where speakers refer to subjective perception of the environment. Verbs most frequently used were those which express a verbal process, with $36.4 \%$, and a mental process, with $28 \%$.

Keywords: deponent verbs; Aulularia; verbal process; transitivity; intransitivity. 


\section{Introducción}

La lengua latina representa para el mundo occidental una fuente inagotable de estudios lingüísticos destinados a la mejor comprensión de la lengua del Lacio e, indirectamente, de nuestra propia lengua española, descendiente de aquella. Efectivamente, un conocimiento más acabado del latín nos capacita para una mejor comprensión del lenguaje humano como fenómeno y una mejor comprensión del español como producto de él. A pesar de sus semejanzas, indudablemente el latín presenta numerosas diferencias morfológicas y sintácticas con respecto al español, diferencias que hacen a este último un sistema lingüístico diferente. Las semejanzas hacen del latín una lengua "más fácil” de asimilar, pero las diferencias la hacen extraña en ciertos aspectos, en los que factores lingüísticos diversos han actuado posibilitando su cambio y evolución al español. Precisamente, el sistema verbal latino llegó a transformarse drásticamente ya en el periodo del latín clásico, dando paso a la desaparición de ciertos tipos verbales con la consiguiente disminución en nuestra comprensión intuitiva (como hispanohablantes) del significado y razón de ser de ellos. Este es el caso de los verbos deponentes latinos, que serían una remanencia de un periodo temprano del indoeuropeo, los cuales a los mismos hablantes del latín clásico ya les resultaban extraños. Es verdad que se ha avanzado bastante en el camino hacia una comprensión cabal de estas formas verbales, pero, sin duda, no se ha logrado un consenso definitivo al respecto. Creemos que la lingüística moderna puede ser una gran herramienta para tal comprensión y que nuevos estudios pueden lograr algo de luz al respecto. Es en esa línea en la que se enmarca este pequeño trabajo, su razón de ser. Además, presentamos este estudio de los verbos deponentes en una obra en particular como una manera de introducir el análisis de estas formas verbales en un futuro marco de estudio más general, el cual deberá englobar diferentes autores y géneros literarios latinos.

En este trabajo se intentará analizar los usos de los verbos deponentes en una obra en particular de Plauto: Ia Aulularia. Para tal efecto, se clasificarán cerca de mil quinientos verbos presentes en esta obra en cuanto a su transitividad e intransitividad léxica, tiempo y modo, con el objetivo de apreciar a grandes rasgos algunas características de su empleo sintáctico. Además, se analizarán los verbos en la medida en que reflejen y codifiquen eventos de diferente grado de objetividad, implicación del sujeto y el contexto en que son utilizados, esto es, según aparezcan en una escena dialogada o un monólogo de algún personaje ${ }^{1}$. Por último, se analizarán específicamente los verbos deponentes en relación a un esquema sintáctico transitivo o intransitivo, y se intentará clasificar estos verbos según el tipo de proceso o clase verbal (mental, relacional, material, existencial y causativo-dispositivo).

Como marco teórico-lingüístico se utilizarán los conceptos de la gramática funcional, pues creemos que logran reflejar de mejor manera la realidad de la lengua. Se hace insostenible la idea de un análisis lingüístico a partir solo de la lengua y no del habla, siguiendo los conceptos de Ferdinad de Saussure. La lingüística funcional entiende a la lengua como un sistema que aporta los medios de expresión apropiados para un fin, en la que sus componentes se relacionan e interconectan para proporcionar un instrumento de la comunicación. Como todo instrumento, puede ser perfeccionado, utilizado, adaptado a las nuevas necesidades expresivas de los hablantes y, ciertamente, modificado en el tiempo. Esta teoría coloca un énfasis importante en la descripción de enunciados y actos de habla, a los que considera estructuras que poseen una

1 Ciertamente, esta comedia plautina posee diversos tipos discursivos y en diferentes niveles de expresión (diálogo de hombres libres, diálogo entre esclavos, diálogo hombre libre - esclavo), los cuales podrían arrojar luz sobre diferencias sintácticas significativas. 
organización jerarquizada o niveles sintáctico-semánticos. Para el análisis lingüístico, utiliza tanto el plano de la sintaxis como el de la semántica y pragmática, aumentando la posibilidad de una descripción más acabada de la lengua.

Para el desarrollo de la gramática funcional ha sido importante la figura de S. Dik como iniciador de la teoría y, para el latín, los estudios de Pinkster (1995). A partir de la descripción de este último, expondremos un breve resumen de la estructura de la oración y sus niveles, dirigido al lector no familiarizado con esta teoría, con el objeto de lograr una mayor comprensión de los conceptos utilizados a lo largo de este trabajo.

\section{Marco conceptual}

\subsection{Estructura de la oración y sus niveles}

La oración se define como una estructura predicativa ${ }^{2}$ que tiene la capacidad de formar un enunciado ${ }^{3}$ o mensaje completo. Esta estructura presenta una jerarquización que involucra diferentes niveles de comunicación. La forma básica que debe adoptar la estructura oracional es el predicado junto con sus constituyentes necesarios u obligatorios que lo completen ${ }^{4}$. El número de constituyentes (argumentos) necesarios dependerá directamente de la semántica del verbo. Hay verbos que no requieren ningún argumento ${ }^{5}$, pues forman un enunciado completo, o pueden necesitar dos o más argumentos.

Marcus Iuliam pulsat

Marco golpea a Julia

En esta oración el predicado es el verbo pulsat, que requiere necesariamente dos cons- tituyentes o argumentos: quien hace la acción de golpear (sujeto-agente), marcado por el caso nominativo, y quien es afectado por dicha acción (objeto-paciente), marcado por el acusativo. También aquí se diferencian las funciones sintácticas de las funciones semánticas. Una función sintáctica es el rol o papel que desempeña una palabra en la interacción con otras, y una función semántica ${ }^{6}$ es el significado que posee una palabra en relación con los restantes constituyentes de la oración. En nuestro ejemplo, Marcus cumple una función sintáctica y semántica de sujeto y agente respectivamente. A su vez, Iuliam cumple una función sintáctica y semántica de objeto y paciente (o afectado) respectivamente. Existen verbos que requieren más de dos constituyentes para completar su significado, tales como dare (dar) o dicere (decir).

Marcus aquam Iuliae dat

Marco da agua a Julia

En este ejemplo, Marcus es sujeto-agente (nominativo), aquam es objeto-afectado (acusativo) y Iuliae es el tercer argumento complemento indirecto-beneficiario (en dativo). Esta estructura (verbo + argumentos) ${ }^{7}$ se encuentra en el nivel representativo necesario, y puede expandirse con otros elementos opcionales que aportan información adicional sobre otros participantes o las circunstancias en que se lleva a cabo la acción ${ }^{8}$, formando así el nivel representativo no necesario. A la vez, existe otro grupo posible de elementos opcionales referidos a la evaluación, juicio o apreciación subjetiva del hablante sobre el evento descrito que forma el nivel interactivo.

2 Entiéndase una estructura predicativa como la combinación de un predicado (frecuentemente un forma verbal) y sus correspondientes elementos necesarios o argumentos (que completan y le dan su sentido) y los elementos opcionales o satélites (adjuntos y disjuntos).

3 El enunciado es la unidad mínima con valor comunicativo que dirige un hablante a un interlocutor.

4 Sin estos constituyentes la frase es agramatical.

5 Verbos que expresan eventos meteorológicos naturales como: tronat (truena), pluit (Ilueve).

6 Algunas funciones semánticas de los argumentos son: agente, paciente, causa, receptor, destinatario, dirección, ubicación.

7 Esta unidad sintáctica se llama predicación nuclear.

8 Estos elementos pueden omitirse sin que se convierta la oración en agramatical. 
Pinkster (1995) denomina a los primeros adjuntos $^{9}$ y a los segundos disjuntos.

\section{Marcus quidem aquam heri luliae dedit}

Marco, ciertamente, dio agua a Julia ayer

Aquí, el adverbio heri proporciona información adicional de tiempo, por lo que cumple la función de adjunto. Por otro lado, la partícula quidem avala la verdad de la oración, por lo que cumple la función de disjunto.

Revisados estos conceptos básicos, seguiremos nuestro análisis con las voces del verbo latino y un tema muy afín: el concepto de transitividad e intransitividad.

\subsection{Las voces del latín}

Como es conocido, en la lengua latina, al igual que en el castellano, la categoría gramatical de voz comprende principalmente dos tipos de voces: activa y pasiva. Tradicionalmente estas marcas gramaticales hacen referencia a la relación entre el sujeto y su predicado, es decir, si el sujeto ejerce la acción verbal o la padece. Es así que la voz activa implicaría que el evento o la acción procede del sujeto, siendo este agente de ella. En cambio, en la voz pasiva el sujeto no ejerce la acción, sino que ella recaería sobre él. Cada una de estas voces se asocia a una forma morfológica específica, en la que resultan verbos activos y verbos pasivos. Además, existen en la lengua latina los Ilamados verbos deponentes, en los que su morfología no concuerda con su voz respectiva. Por esta razón se les ha llamado verbos deponentes, los que poseen forma pasiva pero con sentido activo (deponen su voz pasiva). Este es el cuadro de la gramática tradicional.

Se ha observado que el cuadro descrito pre- senta algunas anomalías difíciles de explicar, como aquella en que algunos verbos con morfología activa expresan características de verbos en voz pasiva: fio (ser hecho), vapulo (ser azotado), venio (ser vendido). Para evitar estas inconsistencias, los gramáticos modernos diferencian entre la voz y la diátesis. Entiéndase por diátesis la asociación inicial que cada verbo determina entre relaciones sintácticas de sus argumentos y sus relaciones semánticas que se le asocian (Moreno Cabrera, 2002: 561) 10 $^{10}$ es decir, la relación disposicional entre el verbo y su(s) argumento(s). La diátesis correspondería a una categoría semántica ${ }^{11}$. En cambio, la voz corresponde a una categoría morfológica, es decir, el sistema de paradigma verbal (marca morfológica) que puede expresar una diátesis determinada. Según esta definición, a una voz le puede comprender más de una diátesis. De esta manera, la voz activa puede expresar variadas diátesis: agentiva, pasiva o afectiva, instrumental, causativa, locativa.

$\begin{array}{ll}\text { Iulius mensam fecit } & \text { (agentiva) } \\ \text { Julio hizo una mesa } & \\ \text { Petra fenestram fregit } & \text { (instrument } \\ \text { La piedra quebró la ventana } & \\ \text { Iulius fit imperator } & \text { (afectiva) } \\ \text { Julio es hecho emperador } & \\ \text { Frigus herbam occidit } & \text { (causativa) } \\ \text { El frío mató la hierba } & \end{array}$

Como se puede apreciar, en todos los casos el verbo está en voz activa (verbo morfológicamente activo), pero expresa diferencias diatéticas evidentes. En todos los casos a la función sintáctica de sujeto (expresado en nominativo) le corresponde una función semántica diferente: agente, paciente, instrumento y causa. En la len-

9 Son los complementos circunstanciales de la gramática tradicional marcados por el caso ablativo. La opcionalidad no los convierte en irrelevantes; como dice Pinkster (1995: 3), "pueden proporcionar información muy importante relativa al tiempo, lugar, circunstancia, causa, condición, finalidad, modo, instrumento, relacionada con la acción o estado denotados por el predicado y sus constituyentes obligatorios".

10 Touratier (1994: 169) define la diátesis como el valor semántico de la voz, esto es, el rol que juega el sujeto con respecto al proceso.

11 Relación semántica que se establece entre el predicado y el sujeto. 
gua latina en general, la voz activa es la voz semánticamente no marcada ${ }^{12}$, puesto que no presenta restricciones diatéticas a priori, y, además, morfológicamente no marcada, en cuanto a que se presenta con una construcción más simple y sintética que la voz pasiva, ya que esta última tiene marca de voz (-r) y una composición analítica en los temas de perfecto (participio perfecto + $\left.s^{\prime 13}\right)^{13}$. En la voz pasiva la relación diatética está condicionada por la estructura oracional, precisamente por la función semántica que le corresponde al sujeto en un verbo pasivo: cumple obligatoriamente la función semántica de afectado o paciente, cuya afectación está dada por un complemento agente ${ }^{14}$ explícito o no. La voz pasiva no es un espejo de la voz activa ${ }^{15}$, es más que eso. La pasiva es una estructura diferente a la activa en los roles sintácticos de sus componentes y, sobre todo, en el número de ellos (de los participantes o actantes). Dos ejemplos sencillos demostrarán tales diferencias:
(1) Quintus Aemiliam vocat Quinto Ilama a Emilia
(Activa)
(2) Aemilia (a Quinto) vocatur
(Pasiva) Emilia es Ilamada (por Quinto)

Se aprecia que el objeto-afectado ${ }^{16}$ (Aemiliam) de la oración en voz activa se convierte en sujeto-paciente de la voz pasiva y, por su parte, el sujeto-agente (Quintus) de la oración activa pasa a ser complemento agente en la pasiva, complemento que puede estar expresado o no (desagentivación) ${ }^{17}$. En la construcción predicativa Aemilia vocatur se observa una pérdida de uno de los actantes (el agente), es decir, se produce una disminución de la valencia ${ }^{18}$ verbal. Al perderse un actante 0 al ser elemento opcional (pasa a conformar un adjunto) el verbo típicamente bivalente (verbo transitivo + objeto) se convierte en monovalente, a manera de verbos intransitivos.

En el caso de los verbos deponentes, se pensó en un momento que estos verbos se acercaban más a la órbita de la voz pasiva ${ }^{19}$, pero dadas ciertas características que no concuerdan con la definición de un verbo pasivo latino ${ }^{20}$, actualmente se tiende a aproximar los deponentes a la voz activa. De hecho, comparten las mismas relaciones semánticas en el caso tanto del sujeto como del objeto. Por ejemplo: ego egredior y ego abeo; ego id opinor y ego id puto. En los

12 "El sistema de voces de una lengua opone la voz no marcada o activa a las demás voces marcadas. La voz no marcada o activa no suele tener ningún morfema especial distintivo y es la forma 'normal' del verbo por defecto" (Moreno Cabrera, 2002: 563).

13 Para la relación entre voz sintética = diátesis no marcada y voz analítica = diátesis marcada, véase Moreno Cabrera (2002: 571).

14 Complemento agente, marcado por el caso ablativo, se refiere a una serie de determinaciones semánticas de diferente significado (animado/inanimado). Agente humano propiamente tal, causa o instrumento. Ver Baños (2009: 391)

15 Una transformación de la activa simplemente. No toda oración activa remite a una pasiva y no toda construcción pasiva es transformable a una activa.

16 Función sintáctica de objeto, función semántica de afectado.

17 La función semántica de agente en voz activa es argumento necesario; en cambio, en pasiva es opcional. Esto pone de manifiesto la utilidad de la pasiva como un mecanismo en el que se coloca el foco en el sujeto-paciente y el agente pierde relevancia. No se expresa ya sea porque el hablante no desea mencionarlo o porque no aporta una información relevante. En ambos casos aumenta la ambigüedad y subjetividad de la expresión.

18 El concepto de actante y valencia fue desarrollado por Tesnière en su libro Éléments de syntaxe structurale (1959). La valencia es un concepto que afecta principalmente a los verbos y que dice relación con el número de actantes (argumentos participantes) que puede aceptar o recibir un verbo para saturarse, es decir, para completar su sentido. Es una analogía al concepto de número de valencia que utiliza la ciencia química para referirse a la cantidad de enlaces químicos que se establecen entre los diversos elementos. A nuestro juicio, la utilización de esta nomenclatura en este apartado se justifica por la mayor claridad que se logra al explicar estos conceptos.

19 Los estudios de P. Flobert (1975), cuyos resultados están expuestos brevemente en Baños (2009).

20 Morfología específica, oposición de una forma activa y cambio de diátesis (Baños, 2009: 385).

21 Se expresa el sujeto para hacer más evidente la semejanza. 
primeros dos ejemplos, ambos sujetos (uno de verbo deponente y el otro de verbo activo) cumplen la función de agentes y, en los dos últimos, ambos verbos son transitivos de dos argumentos, siendo id el complemento acusativo objeto de los dos verbos. A partir de esta semejanza se piensa que los deponentes, al igual que los verbos activos, pueden presentar diátesis muy diversas dependiendo de la semántica del verbo y el grado de transitividad que poseen.

Han aparecido los conceptos de transitividad e intransitividad, los cuales se hace oportuno tratar brevemente.

\subsection{Transitividad e intransitividad}

El término transitividad proviene etimológicamente del verbo latino transeo (infinitivo transire) "ir a través" o "pasar de un lado a otro". Efectivamente, lo que denotan los verbos transitivos es el proceso en que un objeto o individuo traspasa de un sitio o estado a otro, en sentido literal o figurado.

Iulia rosas in aqua ponit

Julia pone las rosas en agua
En este ejemplo, el sujeto-agente Iulia pasa el objeto-afectado rosas de un sitio a otro; entonces decimos que el verbo ponere es transitivo en voz activa. Generalmente la transitividad se relaciona con la voz activa, y no a la inversa. Pero se debe entender la transitividad no tanto como un hecho dado por el léxico del verbo, sino más bien como una característica gradual de los predicados verbales, aunque la clasificación lexical del verbo coloca un límite inicial a dicha gradualidad. Así, podemos decir que un evento puede contener mayores características que lo hagan ser más transitivo que otro evento. Efectivamente, Hopper y Thompson (1980) definen la transitividad como gradualidad, en la que están involucrados diez factores mínimos de carácter semántico que la determinan: participantes, cinética, telicidad o puntualidad, inmediatez, volición, afirmación, modalidad, agentividad, afección, individuación ${ }^{22}$. Se puede decir que una predicación es más prototípica si existe un agente concreto, preferentemente humano, que con voluntaria intencionalidad ejerce una acción puntual, télica, real (modalidad declarativa) y afirmativa, que dirige hacia un afectado directa-

22 Los parámetros que, en la propuesta de Hopper y Thompson (1980), definen el grado de transitividad de una cláusula son los siguientes:

\begin{tabular}{l|l|l}
\hline & \multicolumn{1}{|c}{ HIGH } & \multicolumn{1}{c}{ LOW } \\
\hline A. PARTICIPANTS & 2 or more participants, A and O & 1 participant \\
\hline B. KINESIS & action & non-action \\
\hline C. ASPECT & telic & atelic \\
\hline D. PUNCTUALITY & punctual & non-punctual \\
\hline E. VOLITIONALITY & volitional & non-volitional \\
\hline F. AFFIRMATION & affirmative & negative \\
\hline G. MODE & realis & irrealis \\
\hline H. AGENCY & A high in potency & A low in potency \\
\hline I. AFFECTEDNESS OF O & O totally affected & O not affected \\
\hline J. INDIVIDUATION OF O & O highly individuated & O non-individuated \\
\hline
\end{tabular}

A: Agente; O: Objeto 
mente o por el resultado de ella ${ }^{23}$. De esta manera, dos oraciones con verbos activos transitivos pueden tener diferente grado de transitividad:
(1) Femina hortum videbat Una mujer veía el jardín
(2) Iulius poculum iecit Julio arrojó la copa

Los ejemplos se analizan de la siguiente manera: (1): cinesis: proceso; telicidad: atélico; inmediatez: durativo; afección de objeto: ninguna; individuación del agente: inespecífico. (2): cinesis: acción; telicidad: télico; inmediatez: momentánea; afección de objeto: total; individuación del agente: especifico. Entonces, la oración (2) tiene mayor grado de transitividad que (1). Esto deja en evidencia que una estructura formalmente transitiva (verbo $+\mathrm{CD}$ ) presenta diferencia en su valorización semántica como estructura predicativa transitiva (mayor o menor transitividad).

\section{(1) Davus pecuniam tuam habet Davo tiene tu dinero \\ (2) Pecunia tua a Davo habetur *Tu dinero es tenido por Davo}

En estos ejemplos el verbo habere, siendo léxicamente transitivo, posee una menor transitividad que los anteriores, ya que el objeto de la activa no puede pasar a ser sujeto-paciente de la pasiva ${ }^{24}$. De hecho, una forma de comprobar la transitividad semántica es someter la estructura a su forma pasiva, pues "cuanto más prototípica sea la activa transitiva de un verbo, más prototípica será su pasiva, solo que presentando los rasgos opuestos”25.

\subsection{Los verbos deponentes}

Como ya se ha adelantado, los verbos deponentes conforman un grupo especial en los que la voz no concuerda con su diátesis. Algunos estudios (Flobert, 1975) los relacionan estrechamente con los verbos pasivos, y concretamente con la pasiva intrínseca ${ }^{26}$, con la que compartirían una "diátesis interna". Joffre (1995), partiendo del trabajo de Flobert (1975), afirma que esta "diátesis interna" se refiere a que la acción realizada no rebasa la esfera del sujeto y denota una implicancia del sujeto en el proceso. Se ha visto que más que vincularse a formas pasivas, los deponentes comparten características semánticas que los acercarían a la voz media griega, en la que existe una afectación del sujeto directa o indirectamente. Dentro de la voz media existen verbos que no poseen una contraparte activa, los Ilamados media tantum, que expresan una cantidad de significados muy afines a los verbos deponentes latinos:

1) Movimiento y reposo: sequor, progredior, congredior, proficiscor, moror, etc.

2) Cognitivos: opinor, arbitror, meditor, mentior, obliviscor, etc.

3) Anímicos: irascor, queror, laetor, admiror, etc.

4) Expresivos: loquor, colloquor, fateor, fabulor, etc.

5) Procesos corporales: nascor, morior, etc.

6) Provecho o beneficio: potior, utor, fruor, mereor, etc.

7) Profesiones o hábitos: medicor, negotior, agricolor.

Dejando a un lado las cuestiones de los orígenes de los verbos deponentes, ciertamente

23 Esta definición prototípica se basa en la relación de causación física entre un agente y un paciente (verbos de acción como dar, tomar, golpear, quebrar, etc.), más que en una causación psicológica de carácter intencional (verbos de actividad como ver, decir, querer, conocer, etc.). Algunos estudios cognitivos sugieren que los verbos transitivos de causación psicológica serían más prototípicos que los meramente físicos, ya sea por su frecuencia de uso, o por la adquisición temprana en el desarrollo del lenguaje infantil. Ver Vázquez Rozas (2004).

24 Pinkster (1995: 18) califica a estos acusativos con el verbo habere (verbo de estado más que de acción) no como objetos, sino como argumentos.

25 Baños (2009: 384) citando a Torrego.

26 Algunos autores como A. Ernout y F. Thomas en su Syntaxe latine engloban esta forma de pasiva en los Ilamados verbos medio-pasivos 
consideramos que no se ha logrado llegar a una solución completamente satisfactoria27; lo cierto es que estos verbos son susceptibles de un análisis enmarcados en estructuras predicativas que contienen cierto valor comunicativo. Al igual que los verbos activos, presentan diátesis diversas y formas modales que denotan mayor o menor subjetividad. Este es el plano de análisis que queremos llevar a cabo. Ahora, daremos algunas breves referencias sobre la comedia plautina Aulularia.

\section{La Aulularia}

Esta comedia tiene como protagonista a Euclión, un hombre mayor que posee una joven hija, el cual ha encontrado una olla llena de oro y cuyo carácter, más que el del avaro, es el de un hombre desconfiado. La trama versa sobre el miedo enfermizo de Euclión a perder su olla, trama en la que se suceden una serie de escenas, de monólogos y diálogos de los distintos personajes, en diferentes niveles sociales (hombre libre - hombre libre; hombre libre - esclavo; esclavoesclavo), lo que suponemos debería reflejarse en el modo de expresión y generación de enunciados. Estas características la hacen apta para un análisis de frecuencia de verbos activos, pasivos y deponentes, y un análisis de las implicancias de estos últimos en la construcción del discurso.
Además, es característico de Plauto el lenguaje más coloquial (en comparación con Terencio) que emplea en sus comedias, rasgo que le acerca al lenguaje hablado de su tiempo, aunque no llega a ser soez ${ }^{28}$. Muchos juegos de palabras y sentido le dan viveza y comicidad a su obra, unidos a repeticiones y constantes parataxis que reflejan construcciones que denotan afectividad. Todas estas características se encuentran presentes en la Aulularia, o Comedia de la olla.

Para el análisis de verbos se siguió la edición latina de la obra plautina de W. M. Lindsay de Oxford (Comoediae. T. Macci Plauti. Lindsay. Oxonii, 1952).

\section{Exposición y análisis de datos}

La tabla 1 muestra la frecuencia de verbos que poseen una construcción en voz activa, pasiva y verbos deponentes. Un 87,3\% de los verbos se registraron como activos y solamente un 5,3\% como pasivos, con sus diferentes posibilidades de conjugación. Para los verbos deponentes, se registró una frecuencia del 7,4\%. Esta última cifra está en concordancia con lo esperable en un texto literario latino ${ }^{29}$. De los 81 casos de verbos en voz pasiva, que corresponden a un 5,3\% del total, más del 9o\% se registra como pasiva binaria, confirmando para este texto la tendencia a

\section{TABLA 1}

Frecuencia de verbos según tipo verbal y transitividad

\begin{tabular}{l|r|r|r|r|r|r}
\multicolumn{1}{c|}{ Verbos } & $\%$ & Transitivo & $\%$ & Intransitivo & Total & Total \% \\
\hline Activos & $60 \%$ & 910 & $27 \%$ & 410 & 1320 & $87,30 \%$ \\
\hline Pasivos & $5 \%$ & 77 & $0,30 \%$ & 4 & 81 & $5,30 \%$ \\
\hline Deponentes & $5 \%$ & 72 & $2,70 \%$ & 38 & 110 & $7,40 \%$ \\
\hline Total & $70 \%$ & 1059 & $30 \%$ & 452 & 1511 & $100 \%$ \\
\hline
\end{tabular}

27 Creemos que los verbos deponentes podrían analizarse desde los valores diatéticos de la voz media griega con sus dos valores: una diátesis Ilamada "reflexiva”, en la que la acción sale del sujeto y recae total o parcialmente en él, y otra diátesis que hemos denominado "intensiva”, la que se produce cuando la acción se realiza en interés propio (el sujeto tiene interés especial en ella). Esto implica un trabajo futuro de investigación.

28 Para un análisis extenso de Plauto y su obra puede consultarse las obras de Von Albrecht (1997) y Kenney y Clausen (1989).

29 Flobert (1975) refiere una frecuencia de $7 \%$ para verbos deponentes en un texto latino. 
observar la voz pasiva como una pérdida de valencias e indeterminación del agente. Además, 77 casos comprenden verbos transitivos, dando cuenta del aumento de su posibilidad de pasivización ${ }^{30}$. La tabla también muestra la distribución porcentual de verbos léxicamente transitivos e intransitivos, independientemente de su número de argumentos. Esta distribución léxica, o construcción posible derivada de la semántica verbal, refleja que en esta comedia el número de verbos que tienen la capacidad de una construcción transitiva es del 70\%, considerablemente superior al 30\% de los verbos intransitivos ${ }^{31}$.

En la tabla 2 se presenta la distribución de los verbos en los modos indicativo, subjuntivo, imperativo e infinitivo, y sus respectivos tiempos verbales. En general, los actos de habla en los cuales el componente declarativo, en modo indicativo, es el predominante fueron de un $60 \%$, en comparación con los actos de habla impresivos ${ }^{32}$, en modo subjuntivo e imperativo, que fueron del orden de un $20 \%$ y un $5,5 \%$ respectivamente. Se podría decir que en la obra predominan los actos asertivos o declarativos, en los que el hablante considera determinada situación como real. El análisis de algunos diálogos y monólogos refieren una abundancia de actos de habla desiderativos, en los que el hablante expresa una incertidumbre sobre los hechos o deseos. Se evidencia una carga o un compromiso emocional mayor del hablante en este tipo de locuciones. Por ejemplo, en el diálogo entre Euclión y Stáfila (versos 80-105), 7 verbos están en subjuntivo y 13 en indicativo, y con los mismos personajes en la escena tercera del segundo acto se registraron 7 subjuntivos y 12 indicativos. En el pequeño monólogo de Pitódico (vv. 363-371) se registraron 6 subjuntivos y 7 indicativos. En el largo monólogo de Megadoro, con algunas intervenciones de Euclión comentando sus palabras33, 23 subjuntivos y 29 indicativos; en el diálogo entre ambos que le sigue, 18 subjuntivos y 22 indicativos. En el monólogo de Estróbilo34, donde expone cómo ser un buen esclavo, se registraron 14 subjuntivos y 15 indicativos, en tanto que en el monólogo de Euclión ${ }^{35}$ que le sucede se encontraron 8 subjuntivos y 3 indicativos. Por último, en el pequeño monólogo de Licónides ${ }^{36}$, que refleja inquietud e indecisión, hubo 5 subjuntivos y 2 indicativos. Los imperativos se registraron con mayor abun-

\section{TABLA 2}

Distribución de verbos según modo y tiempo

\begin{tabular}{|c|c|c|c|c|c|c|c|c|c|c|c|c|c|c|c|c|c|c|}
\hline \multirow[b]{2}{*}{ Verbos } & \multicolumn{6}{|c|}{ Indicativo } & \multicolumn{6}{|c|}{ Subjuntivo } & \multicolumn{2}{|c|}{ Imperativo } & \multicolumn{3}{|c|}{ Infinitivo } & \\
\hline & Pres. & Impf. & Fut. & Perf. & PPF & FP & Pres. & Impf. & Fut. & Perf. & PPF & $F P$ & Pres. & Fut. & Pres. & Fut. & Perf. & Total \\
\hline Activos & 452 & 20 & 93 & 188 & 11 & 20 & 228 & 25 & 1 & 23 & 5 & 6 & 72 & 8 & 140 & 1 & 27 & 1320 \\
\hline Pasivos & 10 & 0 & 5 & 28 & 0 & 0 & 5 & 1 & 0 & 2 & 0 & 0 & 0 & 0 & 25 & 0 & 5 & 81 \\
\hline Deponentes & 46 & 1 & 15 & 10 & 0 & 0 & 10 & 1 & 0 & 1 & 1 & 0 & 4 & 0 & 21 & 0 & 0 & 110 \\
\hline Total & 508 & 21 & 113 & 226 & 11 & 20 & 243 & 27 & 1 & 26 & 6 & 6 & 76 & 8 & 186 & 1 & 32 & 1511 \\
\hline
\end{tabular}

30 La pasivización de un verbo transitivo es habitual en una forma binaria (sujeto + verbo); la pasiva ternaria (sujeto + verbo + agente) es lo excepcional (Baños, 2009: 389).

31 En general, la construcción transitiva es la no marcada, es decir, la forma que comúnmente se presenta como la más natural, o la forma primera en la codificación que el hablante tiene de los eventos en que participan dos entidades.

32 Dentro de los impresivos se puede distinguir las órdenes o prohibiciones en modo imperativo y las formas desiderativas expresadas en modo subjuntivo. Ver Baños (2009) pág. 452 y ss.

33 Escena 5, acto III, versos 475-535

34 Escena 1, acto IV, versos 587-607.

35 Escena 1, acto IV, versos 607-615.

36 Escena 9, acto IV, versos 727-730 
dancia en las escenas en que precede una jerarquía de amo y esclavo (Euclión-Stáfila; Euclión y Estróbilo; entre Pitódico y los restantes esclavos, etc.)

Los verbos deponentes registraron un $65 \%$ de uso en modo indicativo, un $12 \%$ en modo subjuntivo, $4 \%$ en modo imperativo y un $19 \%$ en modo infinitivo. En la distribución de los modos subjuntivo e imperativo, a lo largo de la obra, no logramos reflejar una predominancia en los actos de habla impresivos. Sin embargo, el aumento de usos de verbos deponentes (independientemente del modo) se logró percibir en monólogos y diálogos donde los interlocutores hacen referencia a su apreciación subjetiva del entorno, implicando procesos internos del hablante, más que en diálogos y monólogos donde se cuenta o narra un suceso. Es así como se registraron 11 verbos deponentes en el diálogo entre Eunomia y Megadoro37, 14 en el diálogo siguiente entre Euclión y Megadoro ${ }^{38}, 4$ deponentes en el monólogo de Estróbilo ${ }^{39}$ del siervo ideal y 3 en el siguiente cuando encuentra el oro en el templo de la Fidelidad. En los diálogos finales, donde se refleja mayor tensión escénica, como en el diálogo en que Euclión cree que Estróbilo tiene la olla en su poder y exige la devolución ${ }^{40}$, se encontraron 7 deponentes; en el diálogo entre Licónides y Eunomia, 5 deponentes4i; en el diálogo entre Euclión y Licónides ${ }^{42}$, 17 deponentes, y entre Licónides y Estróbilo ${ }^{43}, 7$ deponentes.

Para un mejor análisis, se llevó a cabo una clasificación de los verbos deponentes según la clasificación semántica verbal de ADESSE44, muy similar a la tipología de procesos de Halliday (1985), la cual clasifica jerárquicamente en macroclase, clase y subclase a los diversos tipos verbales. Para los fines de este trabajo, se utilizó solo el nivel de macroclase. Las macroclases comprenden los procesos mentales, procesos relacionales, procesos materiales, conducta, procesos verbales, procesos existenciales, como se expone en el siguiente cuadro:

\section{CUADRO 1}

Clasificación verbal según semántica verbal (ADESSE)

\begin{tabular}{l|l|l}
\hline \multirow{4}{*}{ MACROCLASE } & CLASE & EJEMPLOS \\
\hline \multirow{4}{*}{2 Relacional } & Sensación & Gustar \\
\cline { 2 - 3 } & Percepción & Ver \\
\cline { 2 - 3 } & Cognición & Saber \\
\hline \multirow{2}{*}{ 3 Material } & Atribución & Ser \\
\cline { 2 - 3 } & Posesión & Tener \\
\cline { 2 - 3 } & Espacio & Ir \\
\cline { 2 - 3 } 4 Verbal & Cambio & Abrir \\
\cline { 2 - 3 } & Otros hechos & Coger \\
\hline 5 Existencial & Comportamiento & Reír \\
\hline \multirow{2}{*}{6 Causativo-dispositivo } & Comunicación & Decir \\
\cline { 2 - 3 } & Existencia & Haber \\
\hline & Dispositivos & Atreverse \\
\hline
\end{tabular}

Vemos que, efectivamente, la clasificación tradicional de los verbos deponentes latinos dada más arriba es susceptible de ser ajustada, y se puede clasificar a estos en las grandes áreas semánticas de las macroclases verbales propuestas por ADESSE y, además, ajustarlos incluso a la clase y subclase dentro de ellas:

1) Proceso material: sequor, progredior, congredior, proficiscor (clase Espacio, subclase Desplzamiento); potior, utor, fruor (clase Hecho, subclase Uso).

37 Escena 1, acto II, versos 120-179

38 Escena 2, acto II, versos 180-265.

39 Escena 1, acto IV, versos 587-607.

40 Escena 4, acto IV, versos 624-661.

41 Escena 7, acto IV, versos 682-700.

42 Escena 10, acto IV, versos 731-807.

43 Escena 10, acto V, versos 808-final.

44 El proyecto ADESSE es desarrollado por la Universidad de Vigo bajo la dirección de José Ma García-Miguel. Ver Albertuz (2007). Página web: http://adesse.uvigo.es/, fecha de consulta: 29 de julio de 2013. 
2) Proceso mental: opinor, arbitror, meditor, obliviscor (clase Cognitivos); admiror, irascor, laetor, patior (clase Sensación)

3) Proceso verbal: loquor, colloquor, fateor, fabulor, mentior, queror (clase Comunicación).

4) Conducta: nascor, morior, orior (clase Comportamiento, subclase Vida).

5) Proceso existencial: moror, cunctor (subclase Tiempo)

6) Modulación (causativo-dispositivo): vador.

Para poder ajustar la clasificación tradicional a una clasificación semántica, se reorganizaron los grupos de la siguiente manera: en los procesos mentales se agruparon tanto los cognitivos como los anímicos, ambos dentro de la semántica de procesos que se registran en la interioridad mental del sujeto; los verbos que significan movimientos físicos se agruparon en los procesos materiales, y los que denotan reposos (moror, cunctor) se clasificaron en procesos existenciales, subclase Tiempo.

Teniendo claro el nuevo esquema, los verbos deponentes se clasificaron en las diferentes macroclases expuestas en la siguiente tabla:

\section{TABLA 3}

Distribución de verbos deponentes según macroclase

\begin{tabular}{l|r|r} 
Macroclase & \multicolumn{1}{|l|}{$\mathbf{N}^{\circ}$} & \multicolumn{1}{l}{$\%$} \\
Mental & 31 & $28 \%$ \\
\hline Relacional & 1 & $0,90 \%$ \\
\hline Material & 23 & $21 \%$ \\
\hline Conducta & 6 & $5,50 \%$ \\
\hline Verbal & 40 & $36,40 \%$ \\
\hline Existencial & 4 & $3,70 \%$ \\
\hline Causativo & 5 & $4,50 \%$ \\
\hline Total & 110 & $100 \%$ \\
\hline
\end{tabular}

Los verbos deponentes de mayor frecuencia fueron los que denotan un proceso verbal con un $36,4 \%$, y dentro de estos el verbo loquor y sus derivados con 20 apariciones. Les siguen los verbos de procesos mentales con un $28 \%$, en los que arbitror cuenta con 11 y opinor con 5 apariciones. En los procesos materiales tuvieron mayor frecuencia de aparición los de la subclase de Desplazamiento, como los que denotan movimiento, y entre estos sequor y sus derivados con 11 apariciones.

Los procesos verbales 45 se registran como los eventos de mayor frecuencia con un $36,4 \%$, como podría suponerse dentro del contexto de la obra, en la que la indagación de información y exposición de ella en forma de diálogo ocupa gran parte de esta. Hay que tener presente que estos procesos pretenden específicamente construir realidad a partir de la lengua y transferir información.

La alta frecuencia de procesos mentales ${ }^{46}$ (clase: Cognitivos, Sensación, Percepción) podría denotar una mayor subjetividad del hablante en este tipo de obra literaria, ya que, siendo una pieza teatral de alta interacción entre personajes, el estilo plautino de tipo coloquial los acercaría más al tipo de habla conversacional, donde la subjetividad es muy alta, como lo demuestran los estudios de Scheibman (2001) en el habla inglesa ${ }^{47}$ y de Vázquez Rozas y García-Miguel (2006) en el habla española ${ }^{48}$.

Los procesos materiales registran un $21 \%$, y los que refieren un movimiento o desplazamiento ${ }^{49}$ registran un $74 \%$ de ellos. La alta frecuencia se podría deber a la dinámica de la obra y los numerosos cambios de escena, lo que le da un dinamismo y agilidad muy particular.

45 Loquor y sus derivados (eloquor, proloquor, conloquor), fateor, polliceor, mentior, etc.

46 Arbitror, opinor, patior, conspicor, reor, miror, etc.

47 Según Scheibman (2001), en el discurso conversacional predomina una visión subjetiva del hablante, lo que se explicita en el mayor uso de expresiones que manifiestan la perspectiva del hablante, como son la construcción en primera persona y verbos que denotan procesos mentales.

48 Vázquez Rozas y García-Miguel (2006: 15) dicen: "Hemos comprobado que en el discurso oral predominan los procesos mentales y que son relativamente más frecuentes que en otros géneros los sujetos en primera persona”.

49 Regredere, egredior, congredior, sequor y sus derivados (persequor, subsequor), etc. 
Otro factor que se analizó fue la transitividad léxica de los verbos deponentes, lo que se resume en la siguiente tabla:

\section{TABLA 4}

Distribución de verbos deponentes según su construcción

\begin{tabular}{l|r|r} 
Construción & \multicolumn{1}{|l|}{$N^{\circ}$} & \multicolumn{1}{l}{$\%$} \\
\hline Transitivas & 38 & 34,5 \\
\hline Intransitivas & 72 & 65,5 \\
\hline Total & 110 & 100 \\
\hline
\end{tabular}

Se registró un 34,5\% de cláusulas en construcción transitiva ${ }^{50}$ y un 65,5\% intransitivas. Sin embargo, al analizar las construcciones transitivas o la transitividad propiamente dicha como una gradualidad, siguiendo los parámetros de Hopper y Thompson (1980) expuestos más arriba, encontramos que la construcción prototípicamente transitiva (a pesar de que tuviera $\mathrm{CD}$ ) no se registró en casi ninguna de ellas. La mayoría eran de media a baja transitividad. Esto da cuenta de la baja transitividad de las construcciones con verbos deponentes ${ }^{51}$, lo que podría relacionarse a actos de habla expresados en contextos orales, como refleja el trabajo de Thompson y Hopper (2001). Baja transitividad y baja objetividad es coherente con la función interpersonal del lenguaje hablado52 (no declarativa).

Pensamos que la utilización de verbos deponentes en vez de un similar semántico activo puede corresponder a la intención de hacer más inespecífica una acción. Por ejemplo, el empleo de loquor en vez de dico podría radicar en que el segundo verbo requiere necesariamente un complemento para completar su sentido, en cambio el primero no necesariamente. Loquor puede adquirir una mayor especificidad (transitividad) añadiendo un prefijo verbal como en proloquor $^{53}$. Pero no pasa lo mismo con eloquor, que denota más la procedencia interna del proceso que su exteriorización ${ }^{54}$.

\section{Conclusión}

El análisis general de los verbos presentó un dominio esperable del modo indicativo con respecto al subjuntivo, pero este último con un incremento en su número en monólogos y diálogos donde el componente desiderativo era más evidente. El análisis de los verbos deponentes arrojó que un 7,4\% de la totalidad corresponde a estos verbos y que la relación entre su clase verbal y transitividad podría estar relacionada con actos de habla del discurso oral, donde la carga de procesos mentales y verbales tendería a ser mayor. La baja transitividad de los verbos deponentes se relaciona con su baja especificidad con respecto a los verbos activos, es decir, el uso inespecífico de los deponentes (con su empleo monovalente) en comparación con los activos (bivalente) los hace ideales para su empleo en contextos de baja transitividad y, por consiguiente, de alta subjetividad como es el lenguaje coloquial que nos presenta Plauto en su comedia.

\section{Bibliografía citada}

Albertuz, Francisco, 2007: "Sintaxis, semántica y clases de verbos: clasificación verbal en el

50 Se consideró transitiva toda construcción de verbo + CD. Como CD fueron considerados los complementos objetos, cláusulas completivas y construcciones de Ac + Inf. Si se consideran solo transitivas las formas de verbo + objeto, el número se reduce a solo 23 estructuras transitivas.

51 Está claro que no cumplen con una alta transitividad al exponerlas a la prueba de la pasividad, aunque posean un objeto en caso acusativo.

52 Según Halliday (1985), la función ideativa representa la relación entre el hablante y el mundo real que lo rodea. La función interpersonal permite el establecimiento y mantenimiento de relaciones sociales. Se trata de una función interactiva. La función textual es a través de la cual la lengua establece correspondencia entre ella misma y la situación en la cual se emplea.

53 Por la semántica del prefijo pro- (hacia adelante, adelante)

54 Se podría encontrar la misma relación de específico/inespecífico con el verbo arbitror/puto. 
proyecto ADESSE" en Actas del VI Congreso de Lingüística General, Santiago de Compostela, 3-7 de mayo de 2004, 2015-2030.

Baños, José Miguel, 2009: Sintaxis del latín clásico, Madrid: Liceus.

Kenney, Edward J. y W. V. Clausen (eds.), 1989 [1982]: Historia de la literatura clásica, vol. II: Literatura Latina, Madrid: Gredos.

Ernout, Alfred y Francois Thomas, 1951: Syntaxe latine, París: Librairie C. Klincksieck.

Flobert, Pierre, 1975: Les verbes déponents latins: des origines à Charlemagne, París: Les belles lettres.

Hopper, Paul y Sandra Thompson, 1980: "Transitivity in grammar and discourse", Language 56, 251299.

Joffre, Marie-Dominique, 1995: "Le verbe latin: voix, diathèse, transitivité", L'Information Grammaticale 65(1), 45-47.

Halliday, Michael, 1985: An introduction to functional grammar, Londres: Edward Arnold.

Moreno Cabrera, Juan Carlos, 2002 [2000]: Curso universitario de lingüística general, vol. I: Teoría de la gramática y sintaxis, Madrid: Síntesis.

Pinkster, Harm, 1995: Sintaxis y semántica del latín, Madrid: Ediciones Clásicas.

Scheibman, Joanne, 2001: "Local patterns of subjectivity in person and verb type in American English conversation", Typological Studies in Language 45, 61-90.

Thompson, Sandra y Paul Hopper, 2001: "Transitivity, Clause Structure, and Argument Structure: Evidence from Conversation" en Joan L. Bybee y Paul J. Hopper (eds.): Frequency and the Emergence of Linguistic Structure, Ámsterdam: John Benjamins.
Touratier, Christian, 1994: Syntaxe latine, LouvainLa-Neuve: Peeters.

Vázquez Rozas, Victoria, 2004: "Transitividad prototípica y uso”, Boletín de Lingüística 21, 92-115.

Vazquez Rozas, Victoria y José García-Miguel, 2006: "Transitividad, subjetividad y frecuencia de uso en español” en VII Congrés de Lingüística General: actes, del 18 al 21 d'abril de 2006, Universitat de Barcelona, 102.

Von Albrecht, Michael, 1997 [1994]: Historia de la literatura romana: desde Andrónico hasta Boecio, Barcelona: Herder. 